\title{
Experiential Learning Processes Informing Climate Change Decision Support
}

\author{
SCOTT E. KALAFATIS \\ Falk School of Sustainability, Chatham University, Gibsonia, Pennsylvania \\ JASMINE NEOSH \\ College of Menominee Nation Sustainable Development Institute, Keshena, Wisconsin \\ JULIE C. LIBARKIN \\ Earth and Environmental Sciences, Michigan State University, East Lansing, Michigan \\ KyLE POWYs Whyte \\ Department of Philosophy, Michigan State University, East Lansing, Michigan \\ CHRIS CALDWELL \\ College of Menominee Nation Sustainable Development Institute, Keshena, Wisconsin
}

(Manuscript received 4 January 2019, in final form 13 May 2019)

\begin{abstract}
Climate scientists are increasingly called upon to collaborate with policy makers to develop climate science-informed policy decisions. However, there are concerns that existing professional and cultural boundaries will remain persistent barriers to fulfilling the potential promise of these collaborations. The perception that scientists will be learning by doing while pursuing these efforts does little to assuage these concerns because more research is needed into how scientists actually learn to collaborate more effectively. Using interviews with 18 individuals identified by their peers as particularly successful participants in collaborations between Native American Tribes and climate science organizations, this paper offers suggested practices and examines learning processes underlying the development of these suggestions. The development of the list of suggested practices highlights the extent to which having the right attitude, taking the right actions, and cultivating the right processes are intertwined factors associated with success in these collaborations. Analysis of the learning processes underlying interviewees' suggestions for suggested practices offered five sources of information that frequently led interviewees to reflect on their experiences and gain new knowledge from them. Despite these common trends, each interviewee described a reflection system that they had cultivated to continually monitor and enhance their work in collaborations that was personalized and distinctive from those the other interviewees used. Increased attention to these tailored reflection systems offers a path forward for understanding how experiential learning can most effectively enhance climate change decision support.
\end{abstract}

\section{Introduction}

The need for climate science-informed policy decisions grows each year, and so does the recognition that informed decisions require personal collaborations (Maynard 1998; Dilling and Lemos 2011; Maldonado et al. 2016). Interactions between scientists and potential

Corresponding author: Scott E. Kalafatis, s.kalafatis@ chatham.edu users of climate information are therefore an essential component of society's efforts to successfully address the impacts of climate change. But increased demand for interactions between scientists and potential users of climate information has elicited concerns about scientists' ability to meet these multiplying requests (Kirchhoff et al. 2013) and interest in how individual organizations (Lemos et al. 2014; Briley et al. 2015) or networks (Kalafatis et al. 2015; Dow et al. 2013; Frank et al. 2012) can successfully learn to serve the distinctive 
needs of very different constituencies. Still, these collaborations are often undermined by a lack of understanding across cultural and professional divides (Porter and Dessai 2017). Closing these gaps requires understanding how participants can develop more nuanced and sophisticated understandings of each other's roles and responsibilities in these processes (Porter and Dessai 2017).

This paper uses semistructured interviews with 18 individuals identified by their peers as particularly ethical and effective participants in cross-cultural climate change collaborations to present suggested practices and examine processes they employ to learn to work more effectively in these efforts. These individuals have participated in collaborations exemplifying the importance and challenge of working across professional, cultural, institutional, and historical boundaries: collaborations between those affiliated with Native American Tribes in the United States (hereinafter "Tribes") and climate science organizations (CSOs)—governmental and nongovernmental organizations providing decision support. Though the development of supportive collaborative relationships between Tribes and scientists has been investigated in fields such as anthropology and conservation, such collaborations are a relatively new development in the context of climate science-and their success will depend upon effective learning processes (Whyte 2013b; Williams and Hardison 2013; Smith and Sharp 2012). Challenges surrounding cultural and professional divides in climate change collaborations reflect issues Indigenous peoples and U.S. people of color have pointed out for many decades in other areas of environmental science (Arquette et al. 2002; Brulle and Pellow 2006).

\section{Tribes and climate change collaborations}

Indigenous peoples' efforts to address climate change put the importance and intricacy of these collaborations into particularly stark relief. Many Indigenous peoples trace their own intellectual and scientific traditions to philosophies that track seasonal and interannual changes. Hence, on their own terms, Indigenous peoples have articulated the advantages of engaging with climate science as another knowledge tradition for supporting greater awareness and understanding of environmental change (Whyte 2018; Weatherhead et al. 2010; Hassol 2004; Watt-Cloutier 2015). NonIndigenous scholars and practitioners have perceived that Indigenous peoples are particularly vulnerable to the negative impacts of climate change (Bennett et al. 2014), but also possess unique insight into responding to these impacts (Ford et al. 2016). Furthermore, the
U.S. federal government's trust responsibility legally requires that Tribes and U.S. officials coordinate with one another, continually drawing their governments into engagement in the course of their climatechange-related efforts (Whyte 2013a). In response, Indigenous peoples have drawn on traditions of collaboration (Reo et al. 2017) to not only work with climate scientists, but explore ways to make climate change collaborations more effective (Maldonado et al. 2016; Mandaluyong Declaration 2011; Weatherhead et al. 2010; Maynard 1998).

Still, these collaborations highlight challenges related to interactions facilitating the application of climate science in policy decisions. Establishing trust is essential in climate science collaborations (McNie 2013), but Indigenous peoples have faced centuries of exploitation as subjects in research not designed to enhance their well-being (Smith 2013) that makes experiencing this trust particularly difficult. ${ }^{1}$ Climate change adaptation efforts have raised concerns about power inequities and the associated risks of communities sharing sensitive information with scientists (Williams and Hardison 2013). Whether climate change information is usable is mediated by perceptions of fit - is it credible, accurate, relevant for policy making needs, and timely (Lemos et al. 2012). Realizing this fit is especially difficult for Tribes. Tribes have endured restrictions on their decisionmaking agency that place distinctive and complex limitations on their efforts to translate information into actions addressing climate change (McNeeley 2017). How climate information interplays with existing forms of knowledge also mediates its usability in decisions (Lemos et al. 2012). Engagements between researchers and Indigenous peoples have long revealed assumptions and epistemologies underlying forms of knowledge and underscored that the value of knowledge stems from its utility within the context in which it is used (Agrawal 1995). The wide variation in Indigenous peoples' perspectives on the nature of knowledge and how it relates to their lives underscores that scientists hoping to successfully work with a community need to participate in long-term processes of mutually respectful learning (Whyte 2013b).

\footnotetext{
${ }^{1}$ Interviewees did not focus on ways in which their efforts in these projects could effectively address larger social justice concerns. This was not a specific topic in these interviews, and interviewees focused their attention on practical, tangible ways in which they could enhance the specific projects on which they were working. However, more attention to how these processes relate to the larger historical and contemporary inequities that surround them is given in two other papers related to this project: Kalafatis et al. (2019a,b).
} 


\section{Learning by doing}

In their efforts to identify long-term strategies for better understanding and responding to climate change, The National Research Council (NRC) Committee on America's Climate Choices reports have encouraged decision-makers throughout the United States to pursue adaptive risk management (NRC 2010a,b). ${ }^{2}$ The panel reports frame climate change adaptation as a riskmanagement strategy (NRC 2010a, p. 124) in which understanding of the probability of events, their potential impacts, and the effectiveness of response options will grow over time (NRC 2010c, p. 103; NRC 2010a, p. 124). Under these kinds of conditions, adaptive risk management strategies that frame decision-making as an ongoing process in which participants strengthen their understanding of the challenges they face through monitoring and adjusting to changing conditions should result in better decisions over time (NRC 2010a, p. 124). To successfully support these evolving efforts, both decision-makers and the climate change research enterprise itself will need to pursue "learning by doing" (NRC 2010a, p. 150; NRC 2010b, p. 9).

Learning by doing engages experiential learning methods that immerse adults in experiences and encourage personal reflection that cultivates new skills, attitudes, or ways of thinking (Lewis and Williams 1994). Many Indigenous educational traditions emphasize that the purpose of education is for the learner to freely engage in their own learning experiences, working to explore solutions and understandings of the world independently. The learner then engages with others in the community to reflect on their experiences, receive mentorship, and demonstrate what they believe they have learned more publicly. Hence, one way to characterize Indigenous education approaches is that action is the key vehicle for learning. Indigenous educational scholars have resisted lecture and classroom based approaches to education, favoring instead experiential education that is then scaffolded by reflective conversations, dialogue, and mentorship relationships (Cajete 1994; Bang et al. 2014; Atleo 2006; Simpson 2002; Kulnieks et al. 2013; Evering and Longboat 2013). Dewey (1938) brought attention to the role of experience in Western education, but experiential learning was later packaged as a psychological process featuring sequential natural steps (Seaman et al. 2017).

\footnotetext{
${ }^{2}$ In this section, we follow the uses of terms that are used in the Committee on America's Climate Choices reports. The reports use the terms "adaptive risk management," "iterative risk management," and "adaptive management" interchangeably. Risk is defined as impact multiplied by probability (NRC 2010c, p. 103).
}

Influential models (e.g., Kolb 1984; Schön 1987; Mezirow 1991) have shared a common constructivist approach where individuals have concrete experiences and then use their own active cognition to intentionally enhance knowledge (Fenwick 2001). These models describe individuals' first-order experiences encompassing personal history and present way of being and seeing the world coming into contact with new second-order experiences that generate doubt and discomfort about existing understanding (Malinen 2000, 61-63). Individuals seek continuity between their past and present experiences, so disruptions force a personal decision to preserve continuity through either resisting this new information or learning through using it to update prior understanding (Malinen 2000, 64-66).

Reflection plays a key role in these models (Fenwick 2001) as a process through which individuals analyze their experiences to gain knowledge from them (Jordi 2011). In these models, reflection is depicted as a rational process in which individuals become aware of an issue and then consider the best means of achieving rationally determined goals (Hébert 2015). But recent work has embraced a more expansive conceptualization of reflection that increasingly focuses attention on experiences outside of rational analysis (Hébert 2015). Emotions and other physical felt senses (Stelter 2004) have a role to play in reflection because an individual's bodily sensations affect their responses (Jordi 2011). Practitioners have interactions with the world that are pathic - engaging mood, sensibility, and personal impressions of being in the world (van Manen 2007). Pathic knowledge implicitly resonates in the body as a felt understanding about how to respond to unfolding events that is manifested through action rather than explicitly put into words (van Manen 2007). This understanding is contextual, being framed and embedded in particular relationships, situations, and actions that are constantly evolving (van Manen 2007). Examining the development of pathic knowledge is therefore particularly essential for understanding work where moral and relational issues are amplified (van Manen 2007).

Diverse Indigenous intellectual traditions have long emphasized the importance of both rational and emotionally based reflective processes. Many Indigenous traditions of learning focus heavily on learners developing their own way to process new experiences, practices, and information instead of relying on memorizing guides or protocols. Indigenous learning practices offer guidance on mentorship as a reflective exchange between mentor and learner, where the learner has gone through experiences seeking to implement new practices and reflect on trial and error (Kawagley 2006; Bang et al. 2014; Atleo 2006). Indigenous visioning practices 
are also indicative of reflective practices where, at different stages of life, people engage in a sustained reflection about who they were in the past and where they are going in the future. Returning from a visioning process, an individual is acknowledged by their community for having gone through this process and has new responsibilities and expectations moving forward (Davis 2010). Scholars who write on Indigenous healing, such as D. Million, discuss the importance of reflecting on one's "felt knowledge" for understanding how to navigate complex situations with other people (Million 2013). Indigenous models of restorative justice also emphasize the importance of a reflective process between perpetrators and survivors of violence to arrive at working agreements and norms for how best to move forward (Yazzie 1996-1997).

\section{Methods}

\section{a. Participant selection and interviews}

Exploring the experiences and strategies employed by individuals who had participated in these collaborations particularly successfully first required identifying them. The project team distributed an online survey during May-October 2017 to 204 individuals with experience in climate-related collaborations between Tribes and CSOs. ${ }^{3}$ Thirty Tribe-affiliated respondents in 14 U.S. states and 36 CSO-affiliated respondents in 15 U.S. states and Washington, D.C., provided complete answers (32\% response rate). CSO-affiliated respondents to the survey were largely employed by boundary organizations who receive federal funding. A common example of an agency-sponsored organization in the literature that also appeared frequently in the collaboration projects assessed by the project team was the NOAA-sponsored Regional Integrated Sciences and Assessments (RISA) program. This survey concluded with an open-ended prompt: "Are there individuals or organizations who are pursuing these collaborations in a particularly innovative and ethical way? Please list specific names if possible." The 30 Tribe-affiliated respondents and 36 CSO-affiliated respondents suggested 25 individuals and 12 organizations. Eleven individuals and three organizations had a previous role in the project and were removed. The remaining 14 individuals were contacted about participating in an interview. For the remaining 9 organizations, the project team reviewed materials available online to assess who might

\footnotetext{
${ }^{3}$ Kirby et al. (2019) and Kalafatis et al. (2019a) provide further information regarding this survey's development. Kalafatis et al. (2019b) discusses the survey results.
}

be the best representative. When contacting these individuals for an interview, the project team asked them to forward the request if they believed another person would be a better contact.

The project team completed 18 semistructured interviews during October-November 2017 with individuals affiliated with Tribes, inter-Tribal organizations or Tribal colleges, the U.S. federal government, landscape conservation cooperatives, nonprofit organizations or consulting services, and research universities and extension services. Eight of the interviews predominately represented the perspective of Tribes or Tribal organizations and 10 of the interviews predominately represented the perspective of CSOs responsible for connecting science with policy. The organizations these interviewees were affiliated with were primarily based in 13 U.S. states across California and the Pacific Northwest, Southwest, Great Plains, upper Midwest, and Southeast. This diversity of backgrounds belies the binary distinction between Tribe-affiliated and CSOaffiliated respondents made in this paper, and the personal histories of participants each blur boundaries in distinctive ways, but there are consistent and persistent differences in the professional experience of representing Tribal and non-Tribal entities in the United States the exploration of which can shed light on how Tribes' interests can be better served by collaborations with outsiders.

The interviews covered the following topics: the interviewee's personal and professional history, what needs to happen for these collaborations to be successful (based on their definition of success), what needs to be avoided, how they have prepared for these collaborations, how they assess their preparation and performance, and what advice they would give others in a similar position about taking part in these collaborations. Interview transcriptions were shared with interviewees so they could edit or clarify responses. Interviewees were also allowed to review a version of this paper and provide feedback before its submission for peer review.

\section{b. Analysis}

This research sought 1) to develop a list of suggested practices for successfully participating in these collaborations and 2) to gain insight into the processes through which the interviewees had cultivated their insights into what these suggested practices were. Answering these research questions required an inductive exploration of patterns emerging across contextualized narratives of individuals' personal experiences consistent with the qualitative methods of content analysis (Vaismoradi et al. 2013). For each of these research questions, a series 
TABLE 1. Summary of suggestions for collaborations between Tribes and CSOs. Here, "count" indicates the number of interviews with a suggestion present of the 18 possible.

\begin{tabular}{|c|c|c|}
\hline Suggestion & Description & Count \\
\hline \multicolumn{3}{|c|}{ Having the right attitude } \\
\hline Have commitment & Believe in what you are doing-it is more than a $9-5$ job, it is a responsibility & 6 \\
\hline Know your priorities & Understand your own intentions and goals & 6 \\
\hline Be transparent & Be upfront about these goals so that they can be properly vetted & 8 \\
\hline Have an open heart & Do not go in with preconceived notions or prejudice & 14 \\
\hline Do not be a know-it-all & Do not act like you have a superior understanding & 7 \\
\hline Respect Tribal knowledge & Understand and honor the value and integrity of Tribal knowledge & 10 \\
\hline Acknowledge partnership & Tribes are not stakeholders, but rather are partners with unique authority and concerns & 6 \\
\hline Be adaptable & Recognize differences between Tribes and adapt to the situation & 9 \\
\hline \multicolumn{3}{|c|}{ Taking the right actions } \\
\hline Engage long-term & No one-offs-build long-term relationships with communities & 6 \\
\hline Know the context & Know, acknowledge, and stay updated about the history and key players & 11 \\
\hline Be there in person & Go on site visits and seek out face-to-face interactions & 7 \\
\hline Do helpful things & Be thoughtful about your impact and find ways to reduce existing burdens & 7 \\
\hline Include funding & Incorporate funding into projects for implementation and compensation & 5 \\
\hline Adhere to standards & Know protocols, construe them conservatively, and respect limitations & 8 \\
\hline Listen & Listen closely to what your collaborators say to enhance your understanding & 8 \\
\hline Do not speak for others & Do not speak for Tribes, but facilitate interactions with Tribes' consent & 4 \\
\hline \multicolumn{3}{|c|}{ Cultivating the right processes } \\
\hline No cold calls & Do not cold call-find other approaches like letting others introduce & 4 \\
\hline Tribes lead & Tribes' interests and decision-making authority should direct action & 9 \\
\hline Make engagements valuable & People have limitations, but they will participate if you make it worth their while & 15 \\
\hline Set clear, realistic goals & Make goals explicit and do not set the bar too high & 4 \\
\hline Have the right people & Get the right people in the room for what you are trying to accomplish & 6 \\
\hline Receive needed buy-in & Know, seek out, and receive needed buy-in & 8 \\
\hline Maintain contact & Have consistent interactions and facilitate an iterative process & 8 \\
\hline Provide time & Sufficient time is necessary to allow things to unfold and to overcome challenges & 5 \\
\hline
\end{tabular}

of broad overarching thematic categories and subcategories emerging from close reading of the data were first developed. Quantitative counts of instances in which respondents offered manifest (i.e., explicit) or latent descriptions of particular content were then assessed. A narrative qualitative description that provides a contextualized interpretation of these findings was then developed (Vaismoradi et al. 2013).

\section{Results}

\section{a. Suggested practices}

Table 1 summarizes the suggested practices. They encompassed overarching themes of having the right attitude, taking the right actions, and cultivating the right processes. Having the right attitude reflected ways in which interviewees emphasized that the mindset of participants and how participants present themselves affects their role in collaborations. Commitment to contributing to this work had to be authentic (six interviews) and participants needed to be cognizant of their own goals and intentions and be transparent about those goals and intentions so that others could accurately gauge the value of collaborating with them (six interviews). The overlap between being in touch with and transparent about personal intentions and building reputation is illustrated by the following quote:

the main thing is to have the best intentions-don't do it from a perspective of it just simply being your job. . so if you're coming from the heart and packing tobacco and being genuine about what you're asking for from these folks, it's going to go a lot further than if you're just taking a purely academic approach or just trying to research something or if you're just getting a paycheck.

Participants were encouraged to enter into collaborations with an open heart unclouded by preconceived ideas about collaborators (14 interviews) and be humble about the importance of their own knowledge (seven interviews) while respecting the significance of Tribes' knowledge (10 interviews). The following interview quote describes how being a know-it-all can shut down participants from having the kind of open heart necessary to cultivate important insights through engagement:

Not coming in with the terms established-I'm the expert about whatever, and you're the expert about the other thing. . .It's having your ears open to understand what it is this partner is bringing to the table...I might assume that 
they're experts in range management or something, but it turns out that they know six other things that are super relevant.

CSO-affiliated participants were encouraged to view Tribe-affiliated colleagues as partners-and not stakeholders-with distinctive authority (six interviews) and to be adaptable to the distinctive contextual considerations that each project with Tribes presents (nine interviews).

Taking the right actions reflected that interviewees also emphasized that particular behaviors could contribute or take away from playing a productive role. Interviewees described the importance of these collaborations reflecting long-term relationships (six interviews). Sustaining long-term relationships demonstrates genuine commitment, supports cultivating knowledge about the history and key players surrounding these projects, and keeps participants up-to-date as things change (11 interviews). Seeking out face-to-face interactions, site visits, or even living as a resident in communities was described as means to both enhance understanding and sustain relationships (seven interviews). Connections between spending sustained time in a community and developing the necessary rich understanding of a particular context to understand proper conduct in a collaboration was explicitly articulated by one interviewee: "Not like one class on the people of a region, but they should have to spend time in the community. They should be educated on the history and contemporary issues of the people they intend on working for, because that's what they will have to do is work in the service of a Tribe." Being there in person could also provide opportunities for participants to identify ways to be helpful (seven interviews) such as involving youths in projects that may or may not immediately relate to climate change planning, but could build relationships. One interviewee illustrated how the practicality of these interventions makes them significant:

I realized that when I came back in that I was using their toilet paper. And it would take them three hours to get to a store that had toilet paper. So I brought toilet paper. I brought bottles of water. I brought the kind of things that I was consuming. And then they had no place in which to put the trash, so I'd take the trash back. It's the thing that you know that you are also a consumer within their community, while you're there figuring this all out. And so how can you be a friend in that and to find out how you can engage as a-just a regular human being within the midst.

Incorporating funding to pursue Tribal efforts in projects (five interviews) and carefully adhering to existing standards (eight interviews) such as Tribal
Internal Review Board (IRB) requirements were activities within projects that interviewees described as being supportive. They also emphasized the importance of listening for understanding others' needs and concerns (eight interviews) while not speaking on others' behalf (four interviews). This attention to learning through listening to the words of others rather than imposing your own voice on a collaboration reflected right attitude suggestions about transparency, having an open heart, and being there in person for this CSOaffiliated interviewee:

The first bit of advice I would say is shut up and listen. The second bit is to show up, you know, to be there, and to be there in front of them and give them the opportunity to look you in the eye and tell you what they think, and then you just need to listen. Listen fully and as best as possible try to empathize with what they're saying and not just view and listen to everything through a lens of judgment or self-interest.

Interviewees offered eight suggestions related to cultivating the right processes. They emphasized the importance of avoiding "cold calls" for initiating relationships (four interviews). One interviewee described the value of using presentations at inter-Tribal events to introduce oneself: "we get out to meetings wherever we can that Tribes are represented at and try to make those connections, especially if we have an opportunity to talk about Tribal work. It's a lot easier if we go up and give a presentation about what you're doing, and usually you are approached by someone who's interested in the research." Embedded in this suggestion is the notion that CSOs should not impinge on Tribes' authority to make their own decisions. Along these lines, nine interviewees suggested Tribes should take the lead in collaborations. Tribes' interests and decision-making authority determining whether and how collaborations proceed helps ensure collaborations use Tribes' limited time and resources in a way that is valuable for them (15 interviews). Those working for Tribes are often asked to bear great responsibilities using limited resources, so they must be attentive to the value of devoting their attention to individuals and initiatives. One Tribal organization-affiliated interviewee explained: "we know that we can't do everything. So we try to focus on those things that are important to the Tribe. And then we seek out those science organizations that we think can help us."

The goals these collaborations seek to fulfill should be laid out as clearly as possible and should not be too ambitious (four interviews). Having the right people involved to fulfill whatever the project goals are was also emphasized (six interviews), as was making sure there is 
buy-in from participants and relevant authorities (eight interviews). Finally, interviewees described the importance of providing enough time (five interviews) and remaining in consistent contact to keep track of how the collaboration is proceeding and provide opportunities to learn from engagements between different perspectives (eight interviews). One interviewee involved with facilitating collaboration events explicitly connected the importance of setting realistic goals, identifying the necessary participants, and committing time to aligning motivations:

You have to really spend time to prep to have full human beings showing up and ready to carry on dialogue-and don't get carried away with the mission of trying to stop, or change, federal Indian policy...sometimes it's good enough just to start the dialogue. . .It's how you start, it's setting the table, and getting the right folks at the table. It's, it's setting the right kind of expectations.

\section{b. Reflections producing suggestions}

Descriptions of the learning processes underlying the development of these suggested practices were also analyzed. In experiential learning, new observations disrupt prior understanding (Malinen 2000) and individuals undertake reflection to extract knowledge from these discomforting experiences (Jordi 2011). These interviews revealed five categories of sources of information that frequently elicited these interviewees' reflections on these collaborations and their personal role in them. Table 2 summarizes these sources of information, how frequently they were referenced as well as example references to these sources from interviews. Table 3 summarizes the coding related to reflections for each of the interviews. To facilitate quick comparisons between different perspectives, both of these tables distinguish between interviews with individuals predominately representing the perspective of Tribes or Tribal organizations and those predominately representing the perspective of CSOs or boundary organizations connecting science with policy.

Interactions with collaborators were a reflection source in 14 interviews (of 18). Interactions were a means to uncover opportunities related to the collaboration and/or their collaborators' needs, concerns, or intentions (nine interviews). Interactions were also described as a means of assessing collaborations and calibrating behavior (nine interviews). The CSO quotation provided for interactions in Table 2 offers an example of both roles for interactions as the interviewee described dialogue as both a strategy for understanding and as a strategy for validating that understanding. Seventeen interviews described particular activities that contributed to insights about collaborations and personal roles in them. These activities provided perspective that helped bridge professional and cultural boundaries (seven interviews). The CSO quotation for activities in Table 2 describes how attending events provided perspective on the role of the CSO's work in the midst of other issues Tribes manage. Activities could be lectures, conferences, courses, or other events providing information that enhanced the interviewee's understanding about their collaborations (five interviews). Six interviewees described learning grounded in project experiences specifically. The Tribe/Tribal organization example provided for activities in Table 2 describes an instance where an interviewee gained insight into how to pursue collaborations more successfully through previous negative experience.

Objects were also described as reference points for understanding. IRB standards, contracts tailored to particular projects, or existing protocols were referenced as guides for conduct (seven interviews). In both quotes provided for objects in Table 2, interviewees describe that agreements or protocols provide common standards that participants are expected to follow in collaborations-even if concerns persist that these efforts are not yet sufficient to fully protect Tribes. Objects provided insight into the current state of a collaboration (i.e., meeting minutes and explicit next-action steps) or their collaborator's worldview (i.e., books or art) (five interviews).

Mentors' expertise and dedication also factored into how interviewees conducted collaborations (12 interviews). Mentors played a teaching role through sharing their knowledge with others (12 interviews). Mentors also shared connections and access, particularly through personally introducing the participant to key players (five interviews). In the Tribe/Tribal organizations example provided in Table 2 for mentors, the interviewee first receives mentorship in the form of guidance about undertaking a new project from Tribal elders and then receives mentorship from scientists who facilitated their integration into the project. Mentors also acted as a moral compass that an interviewee relied on to attune their own standards about proper conduct in collaborations (five interviews). The CSO example for mentors in Table 2 describes the importance of having a mentor committed to helping identify when actions are deviating from an appropriate standard. Finally, ideals acting as aspirational guideposts were described as a source of reflection in 15 interviews. These took the form of project-specific goals that interviewees tried to continuously find ways to adhere to as a means of staying on track in particular projects (five interviews). These ideals could also be subjective, moral assessments about 


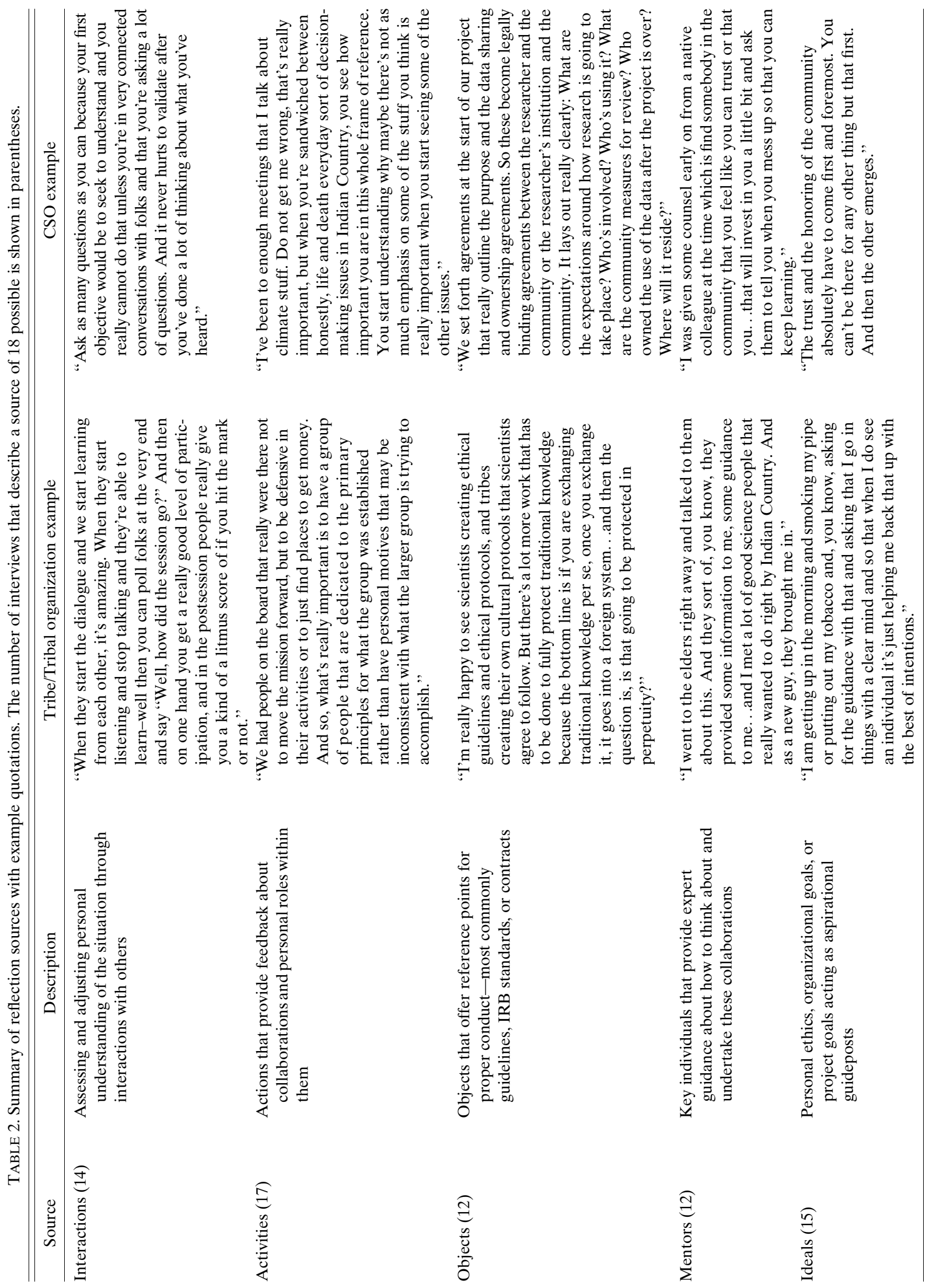


TABLE 3. Summary of reflection coding. The "interviewee" column gives the group that the individual is representing (org is a Tribal organization; boundary is an organization that connects science with policy).

\begin{tabular}{|c|c|c|c|c|c|c|c|c|c|c|c|c|}
\hline \multirow[b]{2}{*}{ Interviewee } & \multicolumn{2}{|c|}{ Interactions } & \multicolumn{3}{|c|}{ Activities } & \multicolumn{2}{|c|}{ Objects } & \multicolumn{3}{|c|}{ Mentors } & \multicolumn{2}{|c|}{ Ideals } \\
\hline & Explore & Calibrate & Bridge & Enhance & Trial & Guides & Insight & Teach & Connect & Compass & Goals & Morals \\
\hline Tribe/org & & $\mathrm{X}$ & $\mathrm{X}$ & & & & & $\mathrm{X}$ & & & & $\mathrm{X}$ \\
\hline Tribe/org & $\mathrm{X}$ & $\mathrm{X}$ & $\mathrm{X}$ & & & & $\mathrm{X}$ & $\mathrm{X}$ & $\mathrm{X}$ & & $\mathrm{X}$ & \\
\hline Tribe/org & & & & & $\mathrm{X}$ & & & & & & $\mathrm{X}$ & \\
\hline Tribe/org & & & $\mathrm{X}$ & & & & & $\mathrm{X}$ & & $\mathrm{X}$ & & $\mathrm{X}$ \\
\hline Tribe/org & $\mathrm{X}$ & & & $\mathrm{X}$ & & $\mathrm{X}$ & & & & & & $\mathrm{X}$ \\
\hline Tribe/org & & $\mathrm{X}$ & $\mathrm{X}$ & & $\mathrm{X}$ & $\mathrm{X}$ & & $\mathrm{X}$ & $\mathrm{X}$ & $\mathrm{X}$ & $\mathrm{X}$ & \\
\hline Tribe/org & $\mathrm{X}$ & & & $\mathrm{X}$ & & & & $\mathrm{X}$ & $\mathrm{X}$ & & & \\
\hline Tribe/org & & $\mathrm{X}$ & & & $\mathrm{X}$ & $\mathrm{X}$ & & & & & & $\mathrm{X}$ \\
\hline $\mathrm{CSO} /$ boundary & & $\mathrm{X}$ & $\mathrm{X}$ & & & $\mathrm{X}$ & & $\mathrm{X}$ & $\mathrm{X}$ & $\mathrm{X}$ & & $\mathrm{X}$ \\
\hline $\mathrm{CSO} /$ boundary & $\mathrm{X}$ & & & $\mathrm{X}$ & & & $\mathrm{X}$ & $\mathrm{X}$ & & & & $\mathrm{X}$ \\
\hline $\mathrm{CSO} /$ boundary & $\mathrm{x}$ & $\mathrm{X}$ & & & $\mathrm{X}$ & & $\mathrm{X}$ & $\mathrm{X}$ & & $\mathrm{X}$ & & $\mathrm{X}$ \\
\hline $\mathrm{CSO} /$ boundary & $\mathrm{X}$ & $\mathrm{X}$ & & $\mathrm{X}$ & & $\mathrm{X}$ & & $\mathrm{X}$ & & & & $\mathrm{X}$ \\
\hline $\mathrm{CSO} /$ boundary & $\mathrm{x}$ & & & $\mathrm{X}$ & & & $\mathrm{X}$ & $\mathrm{X}$ & & & & $\mathrm{X}$ \\
\hline $\mathrm{CSO} /$ boundary & $\mathrm{X}$ & $\mathrm{X}$ & & & $\mathrm{X}$ & & & & & & & \\
\hline $\mathrm{CSO} /$ boundary & & & $\mathrm{X}$ & & & & & $\mathrm{X}$ & $\mathrm{X}$ & & & \\
\hline $\mathrm{CSO} /$ boundary & & $\mathrm{X}$ & & & & $\mathrm{x}$ & & & & & $\mathrm{X}$ & \\
\hline $\mathrm{CSO} /$ boundary & $\mathrm{X}$ & & & & $\mathrm{X}$ & $\mathrm{X}$ & & & & & $\mathrm{X}$ & \\
\hline $\mathrm{CSO} /$ boundary & & & $\mathrm{X}$ & & & & $\mathrm{X}$ & $\mathrm{X}$ & & $\mathrm{X}$ & & $\mathrm{X}$ \\
\hline
\end{tabular}

personal ethics that interviewees relied on to help them conduct themselves appropriately (10 interviews). In the Tribe/Tribal organizations example for ideals in Table 2, the interviewee describes that they frequently attend to deliberately aligning themselves with their own moral intuitions to ensure that they will continue to conduct their project work in an ethically sound manner. The CSO quotation similarly describes that, to be successful, those participating in collaborative work must have a particular moral intention guiding what they do.

\section{Enhancing learning by doing in climate change decision support}

The list of 18 suggested practices that emerged from the interviews-consisting of eight suggestions related to having the right attitude, eight related to taking the right actions, and eight related to cultivating the right processes-echoes existing descriptions of suggested practices related to engagements between science and society. Suggestions for conducting transdisciplinary research also emphasize the importance of clearly defining appropriate project goals, having the right people involved, and receiving buy-in (Lang et al. 2012; Wiesmann et al. 2008). Suggestions for conducting appropriate collaborations with Indigenous partners have emphasized knowing the context; transparency; understanding that Tribes should lead because respecting selfdetermination is a primary concern; respecting Tribal knowledge, capabilities, and limitations; prioritizing attention to the practical impacts of collaborations on
Tribal interests; and respecting existing protocols (e.g., CTKW 2014; Maldonado et al. 2016; Reo et al. 2017). Those focused on enhancing the integration of climate change science into policy decisions more specifically have emphasized making engagements valuable through focusing on attending to the specific needs of decision-makers (Cash et al. 2006; Dilling and Lemos 2011) as well as the importance of CSOs' adaptability in learning to better serve the contexts they are working in (Lemos et al. 2014; Briley et al. 2015). The National Research Council itself has proposed six principles for effective decision support that emphasize things like putting user needs first, focusing on cultivating the process, maintaining contact between producers and users, connecting disciplines and organizations, pursuing long-term stability, and being focused on learning rather than displaying existing expertise (NRC 2009, 40-41). Beier et al. (2017) have updated these principles and have also paired them with specific actions that participants can take to help fulfill them. Meadow et al. (2015, 2016) have integrated the National Research Council's principles into their evaluation of climate change decision support efforts. They have emphasized that approaches for pursuing and assessing collaborative efforts need to be tailored for the contexts they take place within and the types of knowledge exchange that they can feature (Meadow et al. 2015).

This study expands on these preceding efforts in four ways. The first is that it provides some guidance into how an approach for pursuing and evaluating climate change decision support could be tailored for use in the 
particular context of climate change collaborations between Tribes and CSOs. ${ }^{4}$ However, second, these collaborations between Tribes and CSOs often feature particularly stark gaps between the professional, cultural, institutional, and historical boundaries involved in climate change decision support. If these suggestions have helped participants overcome the challenges that emerge in these projects, these suggestions likely can have broader applicability for improving project outcomes in contexts where these gaps are less substantial.

Third, the interviews in this study also emphasized that attitudes, actions, and processes become intertwined in successful collaborations. Being able to articulate strategies like these to connect intentions, actions, and processes can help make sure that intentions about collaboration surrounding climate science translate into more than just lip service (Klenk et al. 2015). Having the right attitude lays the foundation for successful collaborations while a participant taking the right actions demonstrates that they possess those attitudes and can translate them into practical support. With a foundation of appropriate intention and action laid, successful processes that reliably reflect right attitudes and produce right actions can be cultivated with time, patience, and conscious attention. The following interview quote demonstrates how descriptions of attitudes, actions, and processes can be woven together when experienced participants discuss suggestions:

Some things that are helpful are really listening honestly with an open heart and providing enough time to allow thoughts and concerns to come forward. That also means paying attention and being aware of who are the right people in the community to be talking to and to be listening to. Being flexible and allowing enough time for the relationship to build. . .they are often very busy wearing multiple hats and are in contexts where they're being pulled in lots of difficult directions. So being understanding, flexible, patient, and putting forward resources that do not add to the burden that Tribal leaders and your collaborators might already be experiencing. Definitely engage in open dialogue-what you think the research question is and what its importance is might not be the same as what your collaborators think is most important.

The interviewee links attitudes like having an open heart and being adaptable (i.e., understanding, flexible,

\footnotetext{
${ }^{4}$ As mentioned above, these suggestions resonated with other work that has been done on pursuing collaborations with Tribes more generally. Interviewees did not emphasize any ways in which working on climate change collaborations were distinctive from working on other collaborative projects in which Tribes participate. Readers should note, however, that interviewees were not specifically asked to describe such distinctions.
}

and patient) with actions they take-listening and being helpful. These attitudes and actions are in turn connected with process considerations: paying attention so they can understand who the right people are to engage with, providing time for the relationship to build, and maintaining contact so that they can continuously gauge their own understanding of the collaboration.

Fourth, these interviews also offered unique insight into learning processes that contributed to the development of these suggested practices. Climate scientists have been encouraged to pursue "learning by doing" (NRC 2010b, p. 9) in their collaborations with decisionmakers but there has been limited accompanying scholarly attention to how this unfolds effectively in practice. However, Meadow and her colleagues' efforts to integrate the National Research Council's principles into their evaluation of climate change decision support efforts (Meadow et al. 2015, 2016) has provided some guidance. They found that participants drew on their past experiences to follow the principles and identified that incorporating opportunities to reflect on the process would help integrate learning into these processes (Meadow et al. 2016).

Similarly, analysis of the interviewees' personal narratives about their development along with their suggestions for others revealed five sources of information that elicited reflection in the course of their experiences: interactions, activities, objects, mentors, and ideals. Consistent with descriptions about reflection as a process that encompasses concrete rational analysis as well as subjective feelings and emotions (Hébert 2015), the interviewees' observations included references to collecting information in both relatively concrete and subjective ways. On the one hand, interviewees acquired necessary new information about collaborations through formal dialogue about an issue with collaborators or taking courses covering relevant history and law. On the other, they adjusted their behavior based on personal moral precepts such as "don't be a jerk" that contributed to an intuitive sense of what was and was not appropriate conduct. These more intuitive indicators drew on pathic knowledge (van Manen 2007) associated with accessing and interpreting intuitive felt senses (Stelter 2004) about the potential effects of their actions on their relationships with others and their desired role in the world.

These interviews provided evidence that learning how to successfully navigate cross-cultural climate change collaborations involves drawing on a variety of sources of information for reflection as well as both rational and pathic engagements with the observations made. In particular, pursuing the integration between attitudes, actions, and processes described in the suggested practices might even require the ability to hone both 
rational and pathic capabilities. In that case, understanding developing strategies for honing climate scientists' pathic knowledge might be an important strategy for improving climate outreach efforts. Focusing techniques that were developed to assist with psychotherapy have been shown to help identify and draw out these feelings so that they might more effectively support learning through reflection (Jordi 2011).

At the same time, the summary provided in Table 3 revealed no discernable patterns: individual Tribe and CSO-affiliated interviewees each described their own distinctive mix of learning experiences. Participants seemed to have cultivated personalized reflection systems composed of their own unique blend of reflective activities to continually monitor and enhance their work. This finding highlights that even though there were suggested practices offered and documented in this study, effective learning by doing is a deeply personalized process where participants' past history, current experiences, and future goals come into contact with one another in the service of personal and professional growth. Suggested practices have reflective value as objects or ideals that serve as guideposts, but in the pursuit of successful collaborations, participants ultimately relied on their own ability to observe and adapt to conditions as they arose. Enhancing scientists' ability to make use of suggested principles or guidelines and learn by doing through adapting these principles or guidelines appropriately for their work over time will require more attention to helping scientists understand and cultivate their reflective strategies and capacities.

There are many developing areas in the literature where such efforts are emerging and can be expanded. One is the substantial efforts that have emerged around climate change communication (Moser 2016). To understand and help enable successful communication, this literature is encouraging individual scientists and the climate research enterprise as a whole to examine how they relate to others and adapt to their audience (e.g., Rowson and Corner 2015). It also already actively engages the role that emotion plays in communication processes (e.g., Chapman et al. 2017). Another area is through focusing on training for reflection in geoscience education in the classroom, in professional development opportunities, and other continuing education efforts (Kalafatis and Libarkin 2019). A third potential emerging area is attention to volunteer participation in citizen social science (Kythreotis et al. 2019) that more actively incorporates the general public into scientific and political processes addressing climate change. Incorporating the general public into such efforts can make both science and policy more responsive to both social and environmental conditions (Allen 2018; Jasanoff 2003).
An important related point is that the suggested practices and reflection were ways that Tribe-affiliated interviewees assessed whether they should engage in collaborative work with particular scientists or scientific organizations. Schön's own seminal work on reflective practitioners (Schön 1983) advocated for those engaging with experts to use a similar approach for making their projects as successful as possible. Schön argued for suspending both blind faith and disbelief in experts (Schön 1983, p. 296). Instead, Schön encouraged designing processes in ways that allow the expert to reveal their competence and the effectiveness of their contribution over time (Schön 1983, p. 297). The attentiveness of Tribe-affiliated participants to assessing connections between intentions, actions, and processes made by their collaborators is an example of how participants in projects can help create strategies for assessing performance and holding scientists accountable through observation and reflection. $^{5}$

These findings about personalized reflection also invite future research tailored to exploring what factors underlie certain experiences and strategies versus others and how participants' learning experiences affect the collaborative work that they do. At the same time, there is a complementary need for exploration of common ground across professional and cultural boundaries. Both Tribe-affiliated and CSO-affiliated participants similarly rely on interactions, activities, objects, mentors, and ideals to provide insights into how to collaborate effectively with one another. One major limitation of this project is that individual participants were interviewed about their personal learning process. Future research might shed more light on how reflection takes place as a cooperative effort that participants experience together. This shared need for reflection and training about reflection could be leveraged into opportunities to enhance understanding between participants with both similar and different backgrounds, especially if shared reflection processes are encouraged.

\section{Conclusions}

The climate change research enterprise in the United States has been encouraged to pursue "learning by doing" (NRC 2010b, p. 9) to close the gap between climate science and its appropriate application throughout society. However, closing these gaps in ways that will maximize the potential benefits of engagements between scientists and potential users of

\footnotetext{
${ }^{5}$ For more information about how this might relate to trustbuilding in these contexts, see Kalafatis et al. (2019b).
} 
climate information with as little damage done through trial and error as possible requires developing a better understanding of how participants can pursue such learning by doing effectively (Porter and Dessai 2017).

Based on 18 interviews, this paper has detailed a list of suggested practices pertaining to pursuing successful climate change collaborations between Tribes and CSOs in the United States, and assessed the learning processes through which participants developed these suggestions. These conversations revealed the extent to which these suggested practices related to these collaborations wove together having the right attitude, taking the right actions, and cultivating the right processes. This approach to observing and assessing connections between intentions, actions, and processes is an example of both how climate scientists and those who collaborate with them can cultivate strategies for assessing performance and accountability.

Analysis of the learning processes that gave rise to these suggestions revealed that interviewees cultivated their own personalized reflection systems for continually monitoring and enhancing their efforts in collaborations over time. These personalized reflection systems included five sources of information that frequently led interviewees to extract new knowledge from their experiences: interactions, activities, objects, mentors, and ideals. These reflections featured both rational analysis centered on relatively concrete standards as well as more intuitive and pathic sensations providing guidance for understanding right and wrong behavior in collaborations. Attention to the cultivation of these tailored reflection systems and the ways in which they support collaborations between science and policy could offer opportunities to pursue learning by doing with more effective trials and fewer errors.

Acknowledgments. This project was supported by NSF Grant 1540314. This paper would not have been possible without the time, insights, and candor provided by the interviewees. The authors can only claim to have sought to distill the considerable wisdom that these individuals generously shared to support the efforts of society to deal with climate change through cooperation. The authors also acknowledge their appreciation for the insights provided by the peer reviewers that substantially enhanced this paper.

\section{REFERENCES}

Agrawal, A., 1995: Dismantling the divide between indigenous and scientific knowledge. Dev. Change, 26, 413-439, https:// doi.org/10.1111/j.1467-7660.1995.tb00560.x.

Allen, B. L., 2018: Strongly participatory science and knowledge justice in an environmentally contested region. Sci.
Technol. Hum. Values, 43, 947-971, https://doi.org/10.1177/ 0162243918758380.

Arquette, M., and Coauthors, 2002: Holistic risk-based environmental decision-making: A Native perspective. Environ. Health Perspect., 110, 259-264, https://doi.org/10.1289/ ehp.02110s2259.

Atleo, M. R., 2006: The ancient Nuu-Chah-Nulth strategy of Hahuulthi: Education for indigenous cultural survivance. Int. J. Environ. Cult. Econ. Social Sustainability, 2, 153-162.

Bang, M., L. Curley, A. Kessel, A. Marin, E. S. Suzukovich III, and G. Strack, 2014: Muskrat theories, tobacco in the streets, and living Chicago as indigenous land. Environ. Educ. Res., 20, 37 55, https://doi.org/10.1080/13504622.2013.865113.

Beier, P., L. J. Hansen, L. Helbrecht, and D. Behar, 2017: A how-to guide for coproduction of actionable science. Conserv. Lett. 10, 288-296, https://doi.org/10.1111/conl.12300.

Bennett, B. T. M., and Coauthors, 2014: Indigenous peoples, lands, and resources. Climate Change Impacts in the United States: The Third National Climate Assessment, J. M. Melillo, T. T. C. Richmond, and G. W. Yohe, Eds., U.S. Global Change Research Program, 297-317.

Briley, L., D. Brown, and S. E. Kalafatis, 2015: Overcoming barriers during the co-production of climate information for decision-making. Climate Risk Manage., 9, 41-49, https://doi.org/ 10.1016/j.crm.2015.04.004.

Brulle, R. J., and D. N. Pellow, 2006: Environmental justice: Human health and environmental inequalities. Annu. Rev. Public Health, 27, 103-124, https://doi.org/10.1146/ annurev.publhealth.27.021405.102124.

Cajete, G., 1994: Look to the Mountain: An Ecology of Indigenous Education. 1st ed. Kivakí Press, 243 pp.

Cash, D. W., J. C. Borck, and A. G. Patt, 2006: Countering the loading-dock approach to linking science to decision making. Sci. Technol. Hum. Values, 31, 465-494, https://doi.org/10.1177/ 0162243906287547.

Chapman, D. A., B. Lickel, and E. M. Markowitz, 2017: Reassessing emotion in climate change communication. Nat. Climate Change, 7, 850-852, https://doi.org/10.1038/s41558-017-0021-9.

CTKW, 2014: Guidelines for considering traditional knowledges in climate change initiatives. Climate and Traditional Knowledges Workgroup Rep., 109 pp., https://climatetkw.files.wordpress.com/ 2018/05/tks_guidelines_v1.docx.

Davis, L., Ed., 2010: Alliances: Re/Envisioning Indigenous-NonIndigenous Relationships. University of Toronto Press, 400 pp.

Dewey, J., 1938: Experience and Education. Macmillan, 116 pp.

Dilling, L., and M. C. Lemos, 2011: Creating usable science: Opportunities and constraints for climate knowledge use and their implications for science policy. Global Environ. Change, 21, 680-689, https://doi.org/10.1016/j.gloenvcha.2010.11.006.

Dow, K., B. K. Haywood, N. P. Kettle, and K. Lackstrom, 2013: The role of ad hoc networks in supporting climate change adaptation: A case study from the southeastern United States. Reg. Environ. Change, 13, 1235-1244, https://doi.org/10.1007/ s10113-013-0440-8.

Evering, B., and D. R. Longboat, 2013: An introduction to indigenous environmental studies. Contemporary Studies in Environmental and Indigenous Pedagogies, A. Kulnieks, D. R. Longboat, and K. Young, Eds., Sense Publishers, 1-6.

Fenwick, T. J., 2001: Experiential Learning: A Theoretical Critique from Five Perspectives. ERIC Information Series 385, $76 \mathrm{pp}$.

Ford, J. D., L. Cameron, J. Rubis, M. Maillet, D. Nakashima, A. C. Willox, and T. Pearce, 2016: Including indigenous knowledge 
and experience in IPCC assessment reports. Nat. Climate Change, 6, 349-353, https://doi.org/10.1038/nclimate2954.

Frank, K. A., I.-C. Chen, Y. Lee, S. Kalafatis, T. Chen, Y.-J. Lo, and M. C. Lemos, 2012: Network location and policy-oriented behavior: An analysis of two-mode networks of co-authored documents concerning climate change in the Great Lakes region. Policy Stud. J., 40, 492-515, https://doi.org/10.1111/ j.1541-0072.2012.00462.x.

Hassol, S., 2004: Impacts of a Warming Arctic-Arctic Climate Impact Assessment. Cambridge University Press, 139 pp.

Hébert, C., 2015: Knowing and/or experiencing: A critical examination of the reflective models of John Dewey and Donald Schön. Reflective Pract., 16, 361-371, https://doi.org/10.1080/ 14623943.2015.1023281.

Jasanoff, S., 2003: Technologies of humility: Citizen participation in governing science. Minerva, 41, 223-244, https://doi.org/ 10.1023/A:1025557512320.

Jordi, R., 2011: Reframing the concept of reflection: Consciousness, experiential learning, and reflective learning practices. Adult Educ. Quart., 61, 181-197, https://doi.org/10.1177/ 0741713610380439.

Kalafatis, S. E., and J. C. Libarkin, 2019: What perceptions do scientists have about their potential role in connecting science with policy? Geosphere, 15, 702-715, https://doi.org/10.1130/ GES02018.1.

-_, M. C. Lemos, Y.-J. Lo, and K. A. Frank, 2015: Increasing information usability for climate adaptation: The role of knowledge networks and communities of practice. Global Environ. Change, 32, 30-39, https://doi.org/ 10.1016/j.gloenvcha.2015.02.007.

_ J J. C. Libarkin, K. P. Whyte, and C. Caldwell, 2019a: Utilizing the dynamic role of objects to enhance cross-cultural climate change collaborations. Wea. Climate Soc., 11, 113-125, https:// doi.org/10.1175/WCAS-D-17-0115.1.

— , K. P. Whyte, J. C. Libarkin, and C. Caldwell, 2019b: Ensuring climate services serve society: Examining tribes' collaborations with climate scientists using a capability approach. Climatic Change, https://doi.org/10.1007/s10584-019-02429-2, in press.

Kawagley, A. O., 2006: A Yupiaq Worldview: A Pathway to Ecology and Spirit. Waveland Press, $168 \mathrm{pp}$.

Kirby, C., C. Haruo, K. P. Whyte, J. C. Libarkin, C. Caldwell, and R. Edler, 2019: Training is needed to collaborate ethically: Partnerships between Native American tribes and climate science organizations. Gateways: Int. J. Community Engagement, 12, https://doi.org/10.5130/ijcre.v12i1.5894.

Kirchhoff, C. J., M. C. Lemos, and S. Dessai, 2013: Actionable knowledge for environmental decision making: Broadening the usability of climate science. Annu. Rev. Environ. Resour., 38, 393, https://doi.org/10.1146/annurev-environ-022112-112828.

Klenk, N. L., K. Meehan, S. L. Pinel, F. Mendez, P. T. Lima, and D. M. Kammen, 2015: Stakeholders in climate science: Beyond lip service? Science, 350, 743-744, https://doi.org/ 10.1126/science.aab1495.

Kolb, D. A., 1984: Experiential Learning. Prentice Hall, 256 pp.

Kulnieks, A., D. R. Longboat, and K. Young, Eds., 2013: Contemporary Studies in Environmental and Indigenous Pedagogies: A Curricula of Stories and Place. Springer Science and Business Media, $314 \mathrm{pp}$.

Kythreotis, A. P., and Coauthors, 2019: Citizen social science for more integrative and effective climate action: A sciencepolicy perspective. Front. Environ. Sci., 7, https://doi.org/ 10.3389/fenvs.2019.00010.
Lang, D. J., A. Wiek, M. Bergmann, M. Stauffacher, P. Martens, P. Moll, M. Swilling, and C. J. Thomas, 2012: Transdisciplinary research in sustainability science: Practice, principles, and challenges. Sustainability Sci. 7, 25-43, https://doi.org/10.1007/s11625-011-0149-x.

Lemos, M. C., C. J. Kirchhoff, and V. Ramprasad, 2012: Narrowing the climate information usability gap. Nat. Climate Change, 2, 789-794, https://doi.org/10.1038/nclimate1614.

,-- , S. E. Kalafatis, D. Scavia, and R. B. Rood, 2014: Moving climate information off the shelf: Boundary chains and the role of RISAs as adaptive organizations. Wea. Climate Soc., 6 , 273-285, https://doi.org/10.1175/WCAS-D-13-00044.1.

Lewis, L. H., and C. J. Williams, 1994: Experiential learning: Past and present. New Dir. Adult Contin. Educ., 1994 (62), 5-16, https://doi.org/10.1002/ace.36719946203.

Maldonado, J. K., and Coauthors, 2016: The story of Rising Voices: facilitating collaboration between Indigenous and Western ways of knowing. M. Companion and M. S. Chaiken, Eds., Responses to Disasters and Climate Change: Understanding Vulnerability and Fostering Resilience, CRC Press, 15-25.

Malinen, A., 2000: Towards the Essence of Adult Experiential Learning: A Reading of the Theories of Knowles, Kolb, Mezirow, Revans, and Schön. Doctoral dissertation, University of Jyväskylä, 174 pp.

Mandaluyong Declaration, 2011: Mandaluyong Declaration of the Global Conference on Indigenous Women, Climate Change and REDD Plus. Indigenous Women, Climate Change \& Forests, V. Tauli-Corpuz, Ed., Tebtebba Foundation, 289-310.

Maynard, N. G., 1998: Native Peoples-Native Homelands Climate Change Workshop: Circles of Wisdom. U.S. Global Change Research Program Final Rep., 94 pp., https:// downloads.globalchange.gov/nca/nca1/native.pdf.

McNeeley, S. M., 2017: Sustainable climate change adaptation in Indian Country. Wea. Climate Soc., 9, 393-404, https://doi.org/ 10.1175/WCAS-D-16-0121.1.

McNie, E., 2013: Delivering climate services: Organizational strategies and approaches for producing useful climatescience information. Wea. Climate Soc., 5, 14-26, https:// doi.org/10.1175/WCAS-D-11-00034.1.

Meadow, A. M., D. B. Ferguson, Z. Guido, A. Horangic, G. Owen, and T. Wall, 2015: Moving toward the deliberate coproduction of climate science knowledge. Wea. Climate Soc., 7, 179-191, https://doi.org/10.1175/WCAS-D-14-00050.1.

— Z. Guido, M. A. Crimmins, and J. McLeod, 2016: From principles to action: Applying the National Research Council's principles for effective decision support to the Federal Emergency Management Agency's watch office. Climate Serv., 1, 12-23, https://doi.org/10.1016/j.cliser.2016.02.002.

Mezirow, J., 1991: Transformative Dimensions of Adult Learning. Jossey-Bass, 272 pp.

Million, D., 2013: Therapeutic Nations: Healing in an Age of Indigenous Human Rights. University of Arizona Press, 230 pp.

Moser, S. C., 2016: Reflections on climate change communication research and practice in the second decade of the 21st century: What more is there to say? Wiley Interdiscip. Rev.: Climate Change, 7, 345-369, https://doi.org/10.1002/wcc.403.

NRC, 2009: Informing Decisions in a Changing Climate. National Academies Press, 200 pp., https://www.nap.edu/catalog/12626/ informing-decisions-in-a-changing-climate.

, 2010a: Adapting to the Impacts of Climate Change. National Academies Press, 257 pp., https:/www.nap.edu/catalog/12783/ adapting-to-the-impacts-of-climate-change.

, 2010b: Advancing the Science of Climate Change. National Academies Press, 526 pp., https://www.nap.edu/catalog/12782/ advancing-the-science-of-climate-change. 
2010c: Informing an Effective Response to Climate Change. National Academies Press, 346 pp., https://www.nap.edu/ catalog/12784/informing-an-effective-response-to-climate-change.

Porter, J. J., and S. Dessai, 2017: Mini-me: Why do climate scientists' misunderstand users and their needs? Environ. Sci. Policy, 77, 9-14, https://doi.org/10.1016/j.envsci.2017.07.004.

Reo, N. J., K. P. Whyte, D. McGregor, M. P. Smith, and J. F. Jenkins, 2017: Factors that support Indigenous involvement in multiactor environmental stewardship. AlterNative: Int. J. Indigenous Peoples, 13, 58-68, https://doi.org/10.1177/1177180117701028.

Rowson, J., and A. Corner, 2015: The seven dimensions of climate change: Introducing a new way to think, talk, and act. Royal Soc. for the Encouragement of Arts, Manufactures and Commerce and Climate Outreach and Information Network Rep., 30 pp., https://www.thersa.org/globalassets/pdfs/reports/ the-seven-dimensions-of-climate-change.pdf.

Schön, D. A., 1983: The Reflective Practitioner: How Professionals Think in Action. Basic Books, Inc., 374 pp.

- 1987: Educating the Reflective Practitioner: Toward a New Design for Teaching and Learning in the Professions. JosseyBass, 376 pp.

Seaman, J. O., M. Brown, and J. Quay, 2017: The evolution of experiential learning: Tracing lines of research in the JEE. J. Experiential Educ., 40, 1-20, https://doi.org/10.1177/ 1053825916689268.

Simpson, L., 2002: Indigenous environmental education for cultural survival. Can. J. Environ. Educ., 7, 13-25.

Smith, H. A., and K. Sharp, 2012: Indigenous climate knowledges. Wiley Interdiscip. Rev.: Climate Change, 3, 467-476, https:// doi.org/10.1002/wcc. 185 .

Smith, L. T., 2013: Decolonizing Methodologies: Research and Indigenous Peoples. 2nd ed. Zed Books, 256 pp.

Stelter, R., 2004: Embodiment \& learning. Agora, 6, 1-17.

Vaismoradi, M., H. Turunen, and T. Bondas, 2013: Content analysis and thematic analysis: Implications for conducting a qualitative descriptive study. Nurs. Health Sci., 15, 398-405, https://doi.org/10.1111/nhs.12048.

van Manen, M., 2007: Phenomenology of practice. Phenomenol. Pract., 1, 11-30, https://journals.library.ualberta.ca/pandpr/ index.php/pandpr/article/viewFile/19803/15314.

Watt-Cloutier, S., 2015: The Right to Be Cold: One Woman's Story of Protecting Her Culture, the Arctic and the Whole Planet. Penguin, $304 \mathrm{pp}$.

Weatherhead, E., S. Gearheard, and R. G. Barry, 2010: Changes in weather persistence: Insight from Inuit knowledge. Global Environ. Change, 20, 523-528, https://doi.org/10.1016/ j.gloenvcha.2010.02.002.

Whyte, K. P., 2013a: Justice forward: Tribes, climate adaptation and responsibility. Climatic Change, 120, 517-530, https:// doi.org/10.1007/s10584-013-0743-2.

_ 2013b: On the role of traditional ecological knowledge as a collaborative concept: A philosophical study. Ecol. Processes, 2, https://doi.org/10.1186/2192-1709-2-7.

- 2018: What do indigenous knowledges do for indigenous peoples? Keepers of the Green World: Traditional Ecological Knowledge and Sustainability, M. K. Nelson and D. Shilling, Eds., Cambridge University Press, 57-82.

Wiesmann, U., S. Biber-Klemm, W. Grossenbacher-Mansuy, G. H. Hadorn, H. Hoffmann-Riem, D. Joye, C. Pohl, and E. Zemp, 2008: Enhancing transdisciplinary research: A synthesis in fifteen propositions. Handbook of Transdisciplinary Research, G. H. Hadorn et al., Eds., Springer, 433-441, https://doi.org/ 10.1007/978-1-4020-6699-3_29.

Williams, T., and P. Hardison, 2013: Culture, law, risk and governance: Contexts of traditional knowledge in climate change adaptation. Climatic Change, 120, 531-544, https://doi.org/ 10.1007/s10584-013-0850-0.

Yazzie, R., 1996-1997: Hozho Nahasdlii-We are now in good relations: Navajo restorative justice. University of St. Thomas. Law Rev., 9, 117-124. 